\title{
Numerical Solution for High-Order Linear Complex Differential Equations By Hermite Polynomials
}

\author{
Faruk DÜŞÜNCELI' ${ }^{1}$, Ercan ÇELIK ${ }^{2}$
}

ABSTRACT: In this paper, the numerical solutions of complex differential equations are provided by the Hermite Polynomials and carried on two problems. As a result, the exact solutions and numerical one's have compared by tables and graphs that the method is practical, reliable and functional.

Keywords: Hermite polynomials, linear complex differential equations, numerical solution

\section{Yüksek Mertebeden Lineer Kompleks Diferansiyel Denklemlerin Hermite Polinomları ile Nümerik Çözümleri}

ÖZET: Bu makalede lineer kompleks diferansiyel denklemleri hermite polinomları vasıtasıyla nümerik çözümünü sağladık ve iki test problemine uyguladık. Tam çözümler ile nümerik çözümleri tablo ve grafikler ile karşılaştırdık. Sonuç olarak metodumuzun güvenilir, pratik ve kullanışlı olduğunu gördük.

Anahtar Kelimeler:Hermite polinomları, lineer kompleks diferansiyel denklemler, nümerik çözüm

Faruk DÜŞÜNCELİ (0000-0002-2368-7963), Mardin Artuklu Üniversitesi, Mimarlık Fakültesi, Mimarlık Bölümü, Mardin, Türkiye

Ercan ÇELIK (0000-0002-1402-1457), Atatürk Üniversitesi, Fen Fakültesi, Matematik Bölümü, Erzurum, Türkiye

Sorumlu yazar/Corresponding Author: Faruk DÜŞÜNCELİ, farukdusunceli@artuklu.edu.tr 


\section{INTRODUCTION}

Different type of differential equations have been solved with taylor (Sezer and Yalçınbaş, 2009), Bessel (Yüzbaşı et al., 2011), laguerre (Gülsu et al., 2011), hermite (Yüzbaş1 et al., 2011), legendre (Tohidi, 2012;
Düşünceli and Çelik, 2015) and Fibonacci polynomials (Düşünceli and Çelik, 2017). In this paper, the matrix operates between the Hermite polynomials and their derivatives, we utilized the Hermite method to solve linear complex differential equation.

$$
\sum_{n=0}^{m} P_{n}(z) f^{(n)}(z)=g(z)
$$

with the initial conditions

$$
f^{(t)}(\alpha)=\vartheta_{t} \quad t=0,1, \ldots, m-1
$$

We accept $f(z)$ is unknown function, $P_{n}(z)$ and $g(z)$ are analytical functions in the circular domain which $D=\left\{z=x+i y, z \in C,|z| \leq r, r \in R^{+}\right\} ; \quad \alpha \in D, \quad \vartheta_{t}$ is appropriate complex or real constant.

Suppose that the solution of (1) under the initial conditions (2) is approximated

$$
f(z)=\sum_{n=0}^{N} a_{n} H_{n}(z), z \in D
$$

which is the Hermite series of the unknown function $f(z)$, where all of $a_{n}$ are the Hermite coefficients to be determined.Hermite polynomials defined by

$$
H_{n}(z)=n ! \sum_{m=0}^{\left[\frac{n}{2}\right]} \frac{(-1)^{m}}{m !(n-2 m) !}(2 z)^{n-2 m}
$$

Where $\left[\frac{n}{2}\right]=\frac{n}{2}$ if $n$ is even and $\left[\frac{n}{2}\right]=\frac{n-1}{2}$ if $n$ is odd and we use the collocation points

$$
z_{p p}=\frac{r}{N} p e^{\frac{i \theta}{N} p}, 0<\theta \leq 2 \pi, r \in R^{+}, p \in 0,1, \ldots, N
$$




\section{MATERIAL AND METHOD}

We can write the desired solution $f(z)$ of Equation (3)

$$
f(z)=H(z) A
$$

where

$$
H(z)=\left[\begin{array}{llll}
H_{0}(z) & H_{1}(z) & \ldots & H_{N}(z)
\end{array}\right]
$$

and

$$
A=\left[\begin{array}{llll}
a_{0} & a_{1} & \ldots & a_{N}
\end{array}\right]^{T}
$$

The Hermite polynomials $H_{n}(z)$ can be formed in matrix form as

$$
H(z)=Z(z) B^{T}
$$

where

$$
Z(z)=\left[\begin{array}{lllll}
1 & Z & z^{2} & \cdots & z^{N}
\end{array}\right]
$$

and whether $\mathrm{N}$ is odd,

$B$

$$
=\left[\begin{array}{ccccccc}
0 ! \frac{(-1)^{0}}{0 ! 0 !} 2^{0} & 0 & 0 & 0 & 0 & \cdots & 0 \\
0 & 1 ! \frac{(-1)^{0}}{0 ! 1 !} 2^{1} & 0 & 0 & 0 & \cdots & 0 \\
2 ! \frac{(-1)^{1}}{1 ! 0 !} 2^{0} & 0 & 2 ! \frac{(-1)^{0}}{0 ! 2 !} 2^{2} & 0 & 0 & \cdots & 0 \\
0 & 3 ! \frac{(-1)^{1}}{1 ! 1 !} 2^{1} & 0 & 3 ! \frac{(-1)^{0}}{0 ! 3 !} 2^{3} & 0 & \cdots & 0 \\
4 ! \frac{(-1)^{2}}{2 ! 0 !} 2^{0} & 0 & 4 ! \frac{(-1)^{1}}{1 ! 2 !} 2^{2} & 0 & 4 ! \frac{(-1)^{0}}{0 ! 4 !} 2^{4} & \cdots & 0 \\
\vdots & \vdots & \vdots & \vdots & \ddots & \vdots \\
0 & n ! \frac{(-1)\left(\frac{n-1}{2}\right)}{\left(\frac{n-1}{2}\right) ! 1 !} 2^{1} & 0 & n ! \frac{(-1)^{\left(\frac{n-3}{2}\right)}}{\left(\frac{n-3}{2}\right) ! 3 !} 2^{3} & 0 & \cdots & n ! \frac{(-1)^{0}}{0 ! n !} 2^{n}
\end{array}\right]_{N+1 x N+1}
$$


whether $\mathrm{N}$ is even,

$$
B=\left[\begin{array}{ccccccc}
0 ! \frac{(-1)^{0}}{0 ! 0 !} 2^{0} & 0 & 0 & 0 & \cdots & 0 & 0 \\
0 & 1 ! \frac{(-1)^{0}}{0 ! 1 !} 2^{1} & 0 & 0 & \cdots & 0 & 0 \\
2 ! \frac{(-1)^{1}}{1 ! 0 !} 2^{0} & 0 & 2 ! \frac{(-1)^{0}}{0 ! 2 !} 2^{2} & 0 & \cdots & 0 & 0 \\
0 & 3 ! \frac{(-1)^{1}}{1 ! 1 !} 2^{1} & 0 & 3 ! \frac{(-1)^{0}}{0 ! 3 !} 2^{3} & \cdots & 0 & 0 \\
4 ! \frac{(-1)^{2}}{2 ! 0 !} 2^{0} & 0 & 4 ! \frac{(-1)^{1}}{1 ! 2 !} 2^{2} & 0 & \cdots & 0 & 0 \\
\vdots & \vdots & \vdots & \vdots & \ddots & \vdots & \vdots \\
n ! \frac{(-1)^{\left(\frac{n}{2}\right)}}{\left(\frac{n}{2}\right) ! 0 !} 2^{0} & 0 & n ! \frac{(-1)^{\left(\frac{n-2}{2}\right)}}{\left(\frac{n-2}{2}\right) ! 2 !} 2^{2} & 0 & \cdots & n ! \frac{(-1)^{0}}{0 ! n !} 2^{n} & 0
\end{array}\right]_{N+1 \times N+1}
$$

Then, the relation between the matrix $H(z)$ and its derivatives $H^{\prime}(z), H^{(2)}(z), \ldots, H^{(n)}(z)$ are

$$
\begin{gathered}
H^{\prime}(z)=H(z) K^{T} \\
H^{(2)}(z)=H(z)\left(K^{T}\right)^{2} \\
\vdots \\
H^{(n)}(z)=H(z)\left(K^{T}\right)^{n}
\end{gathered}
$$

where

$$
K=\left[\begin{array}{ccccccc}
0 & 0 & 0 & 0 & 0 & \cdots & 0 \\
1 & 0 & 0 & 0 & 0 & \cdots & 0 \\
0 & 2 & 0 & 0 & 0 & \cdots & 0 \\
0 & 0 & 3 & 0 & 0 & \cdots & 0 \\
0 & 0 & 0 & 4 & 0 & \cdots & 0 \\
0 & 0 & 0 & 0 & 5 & \cdots & 0 \\
\vdots & \vdots & \vdots & \vdots & \vdots & \ddots & \vdots \\
0 & 0 & 0 & 0 & 0 & \cdots & N \\
0 & 0 & 0 & 0 & 0 & \cdots & 0
\end{array}\right]_{N+1 \times N+1}
$$

By using the relations (6) and (7) we obtain the relation

$$
f^{(n)}(z)=H^{(n)}(z) K^{T} A=H(z)\left(K^{T}\right)^{n} A=Z(z) B^{T}\left(K^{T}\right)^{n} A
$$

By changing the collocation points $z=z_{p p}$ into the relation (8), we get the following matrix equations 


$$
f^{(n)}\left(z_{p p}\right)=Z\left(z_{p p}\right) B^{T}\left(K^{T}\right)^{n} A, p \in 0,1, \ldots, N
$$

For $p=0,1, \ldots, N$, we can write the relation (9)

$$
\begin{gathered}
f^{(n)}\left(z_{00}\right)=Z\left(z_{00}\right) B^{T}\left(K^{T}\right)^{n} A \\
f^{(n)}\left(z_{11}\right)=Z\left(z_{11}\right) B^{T}\left(K^{T}\right)^{n} A \\
\vdots \\
f^{(n)}\left(z_{N N}\right)=Z\left(z_{N N}\right) B^{T}\left(K^{T}\right)^{n} A
\end{gathered}
$$

where

$$
Z=\left[\begin{array}{c}
Z_{00} \\
Z_{11} \\
\vdots \\
Z_{N N}
\end{array}\right]=\left[\begin{array}{ccccc}
Z_{0}\left(z_{00}\right) & Z_{1}\left(z_{00}\right) & Z_{2}\left(z_{00}\right) & \cdots & Z_{N}\left(z_{00}\right) \\
Z_{0}\left(z_{11}\right) & Z_{1}\left(z_{11}\right) & Z_{2}\left(z_{11}\right) & \cdots & Z_{N}\left(z_{11}\right) \\
\vdots & \vdots & \vdots & \vdots & \vdots \\
Z_{0}\left(z_{N N}\right) & Z_{1}\left(z_{N N}\right) & Z_{2}\left(z_{N N}\right) & \cdots & Z_{N}\left(z_{N N}\right)
\end{array}\right]
$$

Let us modify the collocation points (4) into equation(1),

$$
\sum_{n=0}^{m} P_{n}\left(z_{p p}\right) f^{(n)}\left(z_{p p}\right) A=g\left(z_{p p}\right)
$$

We attain the basic matrix equation of the relations (8)-(10),

$$
\sum_{n=0}^{m} \sum_{p=0}^{N} P_{n}\left(z_{p p}\right) Z\left(z_{p p}\right) B^{T}\left(K^{T}\right)^{n} \mathrm{~A}=\sum_{p=0}^{N} G_{p}
$$

where

$P_{n}=\left[\begin{array}{cccc}P_{n}\left(z_{00}\right) & 0 & \cdots & 0 \\ 0 & P_{n}\left(z_{11}\right) & \cdots & 0 \\ \vdots & \vdots & \vdots & \vdots \\ 0 & 0 & \cdots & P_{n}\left(z_{N N}\right)\end{array}\right]$ and $G_{p}=\left[\begin{array}{c}g\left(z_{00}\right) \\ g\left(z_{11}\right) \\ \vdots \\ g\left(z_{N N}\right)\end{array}\right]$

Since the A is unknown and should be determined that the matrix equation (11) could be rewritten in the subsequent form:

$$
W A=G \operatorname{or}[W ; G]=\left[w_{p q} ; g_{p}\right] p, q=0,1, \ldots, N
$$

where,

$W=\sum_{n=0}^{m} \sum_{p=0}^{N} P_{n}\left(z_{p p}\right) Z\left(z_{p p}\right) B^{T}\left(K^{T}\right)^{n}$ and $A=\left[\begin{array}{llll}a_{0} & a_{1} & \ldots & a_{N}\end{array}\right]^{T}$

or real constant. 
We write the matrix shape of the initial conditions (2) by the aid of (8),

$$
f^{(t)}(\alpha)=H(\alpha)\left(K^{T}\right)^{t} A=\vartheta_{t} \quad t=0,1, \ldots, m-1
$$

In another hand the matrix shape of the initial conditions could be reformed as

$$
U_{t} A=\vartheta_{t} \quad t=0,1, \ldots, m-1
$$

where

$$
U_{t}=H(\alpha)\left(K^{T}\right)^{t} \quad t=0,1, \ldots, m-1
$$

the augmented form of these equations are

$$
\left[U_{t} ; \vartheta_{t}\right]=\left[u_{t 0}, u_{t 1}, \ldots, u_{t N} ; \vartheta_{t}\right] \quad t=0,1, \ldots, m-1
$$

Finally, to find the unknown Hermite coefficientsconnected to the approximate solution of the problem (1) under the initial conditions (2), we require to replace them rows of (13) by the last $m$ rows of the augmented matrix (12) and hence we have new augmented matrix

$$
[\widetilde{W} ; \tilde{G}]=\left[\begin{array}{cccccc}
w_{00} & w_{01} & \cdots & w_{0 N} & ; & g_{0} \\
w_{10} & w_{11} & \cdots & w_{1 N} & ; & g_{1} \\
\vdots & \vdots & \vdots & \vdots & \vdots & \vdots \\
w_{N-m 0} & w_{N-m 1} & \cdots & w_{N-m N} & ; & g_{N} \\
u_{00} & u_{01} & \cdots & u_{0 N} & ; & \vartheta_{0} \\
u_{10} & u_{11} & \cdots & u_{1 N} & ; & \vartheta_{1} \\
\vdots & \vdots & \cdots & \vdots & \vdots & \vdots \\
u_{m-10} & u_{m-11} & \cdots & u_{m-1 N} & ; & \vartheta_{m-1}
\end{array}\right]
$$

or the matrix equation

$$
\widetilde{W} A=\tilde{G}
$$

If can rewrite (15) in the form and the Ais uniquely set. The solution is given by the Hermite series are determined. And so on, the $m$ th order linear complex differential equation under the initial conditions has an approximated. We can control the precision of the acquired solutions. Since the Hermite series are numerical solution of (1). So the equation should be approximately efficient for 


$$
\begin{gathered}
z=z_{j} \in D, j=0,1,2, \ldots \\
E\left(z_{j}\right)=\left|\sum_{n=0}^{m} P_{n}\left(z_{j}\right) f^{(n)}\left(z_{j}\right)-g\left(z_{j}\right)\right| \cong 0
\end{gathered}
$$

or

$E\left(z_{j}\right) \leq 10^{-l_{j}} \quad\left(l_{j}\right.$ is any positive integer $)$

If $\max 10^{-l} l_{j}=10^{-l}$ is described, then the truncation limit $\mathrm{N}$ is put on until the values $E\left(z_{j}\right)$ at eachof the points $z_{j}$ becomes smaller than the prescribed $10^{-l}$.

\section{RESULTS AND DISCUSSION}

In this part, two examples are given to illustrate the accuracy and effectiveness of the proposed way and all of them are complemented on a computer by using programs typed in Matlab. Therefore, we have recorded in tables, the values of the exact solution

$$
\begin{aligned}
& f(x, y)=x(573 / 9223372036854775808+(21 i) / 144115188075855872) \\
&+ y(-21 / 144115188075855872 \\
&+(573 i) / 9223372036854775808) \\
&+(x+y i)^{2}(-18014398509481987 / 36028797018963968 \\
&+(53 i) / 576460752303423488) \\
&+(x+y i)^{3}(-159 / 2305843009213693952 \\
&-(7 i) / 36028797018963968) \\
&+(x+y i)^{4}(1485316528861191 / 36028797018963968 \\
&-(11906580003201 i) / 36028797018963968) \\
&+(x+y i)^{5}(1666248956492659 / 2305843009213693952 \\
&-(41586247975829 i) / 36028797018963968) \\
&+144115188075855857 / 144115188075855872 \\
&-(19 i) / 2305843009213693952
\end{aligned}
$$

For $\mathrm{N}=10$, 


$$
\begin{aligned}
& f(x, y)=x(13882071 / 147573952589676412928 \\
& \text { - (6532991i)/18446744073709551616) } \\
& +y(6532991 / 18446744073709551616 \\
& +(13882071 i) / 147573952589676412928) \\
& +(x+y i)^{2}(-2305843009202906759 / 4611686018427387904 \\
& \text { - (3280233i)/2305843009213693952) } \\
& +(x+y i)^{3}(-1814333 / 18446744073709551616 \\
& +(735701 i) / 2305843009213693952) \\
& +(x+y i)^{4}(47986826942415845 / 1152921504606846976 \\
& +(38497718388899 i) / 576460752303423488) \\
& +(x+y i)^{5}(23264094237931 / 18446744073709551616 \\
& \text { - (34829294771i)/2305843009213693952) } \\
& +(x+y i)^{6}(-792491809524217 / 576460752303423488 \\
& \text { - (2823403318151i)/288230376151711744) } \\
& +(x+y i)^{7}(248913431329 / 4611686018427387904 \\
& \text { - (159064944217i)/576460752303423488) } \\
& +(x+y i)^{8}(13170887529351 / 576460752303423488 \\
& +(378968311233 i) / 288230376151711744) \\
& +(x+y i)^{9}(-658775106425 / 9223372036854775808 \\
& +(4512177617 i) / 1152921504606846976) \\
& +(x+y i)^{10}(-29038783659 / 288230376151711744 \\
& \text { - (23378868389i)/144115188075855872) } \\
& +9223372036851657523 / 9223372036854775808
\end{aligned}
$$


The solutions of the linear complex differential equation for $\mathrm{N}=3,5$ and 10 are obtained. The absolute errors shown in Tables 1,2 and in Figures 1,2.

Table 1 Comparison of real parts of the exact solution and numerical one's for some values

\begin{tabular}{crrrr}
\hline \multicolumn{1}{c}{$z_{j}$} & Exact solution(Real) & $\mathrm{N}=3$ & $\mathrm{~N}=5$ & $\mathrm{~N}=10$ \\
\hline$-.9(1+\mathrm{i})$ & .8908207824 & 1 & .6216215573 & .8908892455 \\
$-.8(1+\mathrm{i})$ & .9317999001 & 1 & .6966493057 & .9318501705 \\
$-.7(1+\mathrm{i})$ & .9600062080 & 1 & .7647768674 & .9600393451 \\
$-.6(1+\mathrm{i})$ & .9784066646 & 1 & .8252866747 & .9895949000 \\
$-.5(1+\mathrm{i})$ & .9895848832 & 1 & .8775540316 & .9895949000 \\
$-.4(1+\mathrm{i})$ & .9957335935 & 1 & .9210479812 & .9957378882 \\
$-.3(1+\mathrm{i})$ & .9986500259 & 1 & .9553321731 & .9986514289 \\
$-.2(1+\mathrm{i})$ & .9997333347 & 1 & .9800657301 & .9997336172 \\
$-.1(1+\mathrm{i})$ & .9999833333 & 1 & .9950041154 & .9999833512 \\
$0(1+\mathrm{i})$ & & 1 & & 1 \\
\hline $.1(1+\mathrm{i})$ & .9999833333 & 1 & .9950041298 & .9999833511 \\
$.2(1+\mathrm{i})$ & .9997333347 & 1 & .9800661925 & .9997336139 \\
$.3(1+\mathrm{i})$ & .9986500259 & 1 & .9553356851 & .9986514034 \\
$.4(1+\mathrm{i})$ & .9957335935 & 1 & .9210627805 & .9957377771 \\
$.5(1+\mathrm{i})$ & .9895848832 & 1 & .8775991953 & .9895945485 \\
$.6(1+\mathrm{i})$ & .978406646 & 1 & .8253990566 & .9784252442 \\
$.7(1+\mathrm{i})$ & .960006208 & 1 & .7650197690 & .9600372394 \\
$.8(1+\mathrm{i})$ & .931799900 & 1 & .6971228821 & .9318457566 \\
$.9(1+\mathrm{i})$ & .890820782 & 1 & .6224749574 & .8908805837 \\
\hline
\end{tabular}

Table 2 Comparison of imaginer parts of the exact solution and numerical one's for some values

\begin{tabular}{crrrr}
\hline$z_{j}$ & Exact solution(Im.) & $\mathrm{N}=3$ & $\mathrm{~N}=5$ & $\mathrm{~N}=10$ \\
\hline$-.9(1+\mathrm{i})$ & -.8040981746 & -.81 & -.8101521967 & -.8043179038 \\
$-.8(1+\mathrm{i})$ & -.6370882357 & -.64 & -.6400242974 & -.6372208337 \\
$-.7(1+\mathrm{i})$ & -.4886930379 & -.49 & -.4899727890 & -.4887680105 \\
$-.6(1+\mathrm{i})$ & -.3594816533 & -.36 & -.3599629365 & -.3595206898 \\
$-.5(1+\mathrm{i})$ & -.2498263975 & -.25 & -.2499713353 & -.2498445938 \\
$-.4(1+\mathrm{i})$ & -.1599544898 & -.16 & -.1599838390 & -.1599617215 \\
$-.3(1+\mathrm{i})$ & -.0899919000 & -.09 & -.0899934881 & -.0899941321 \\
$-.2(1+\mathrm{i})$ & -.0399992888 & -.04 & -.0399984374 & -.0399997218 \\
$-.1(1+\mathrm{i})$ & -.0099999888 & -.01 & -.0099998850 & -.0100000001 \\
$0(1+\mathrm{i})$ & 0 & 0 & & 0 \\
\hline $.1(1+\mathrm{i})$ & -.0099999888 & -.01 & -.009999850 & -.0100000000 \\
$.2(1+\mathrm{i})$ & -.0399992888 & -.04 & -.0399973324 & -.0399997251 \\
$.3(1+\mathrm{i})$ & -.0899919000 & -.09 & -.0899850972 & -.0899941575 \\
$.4(1+\mathrm{i})$ & -.1599544898 & -.16 & -.1599484800 & -.1599618328 \\
$.5(1+\mathrm{i})$ & -.2498263975 & -.25 & -.2498634277 & -.2498449507 \\
$.6(1+\mathrm{i})$ & -.3594816533 & -.36 & -.3596944279 & -.3595216345 \\
$.7(1+\mathrm{i})$ & -.4886930379 & -.49 & -.4893924366 & -.4887702076 \\
$.8(1+\mathrm{i})$ & -.6370882357 & -.64 & -.6388928054 & -.6372254971 \\
$.9(1+\mathrm{i})$ & -.8040981746 & -.81 & -.8081132113 & -.8043271515 \\
\hline
\end{tabular}




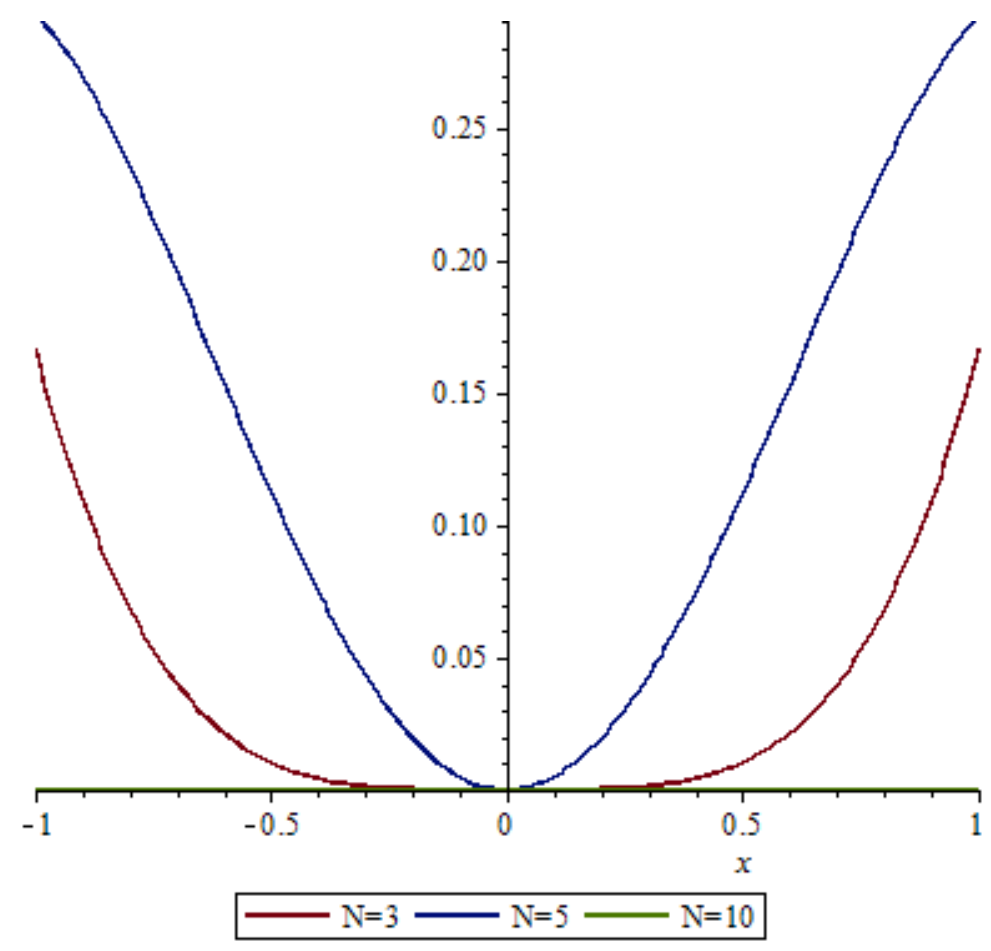

Figure 1. The real parts of the absolute errors functions

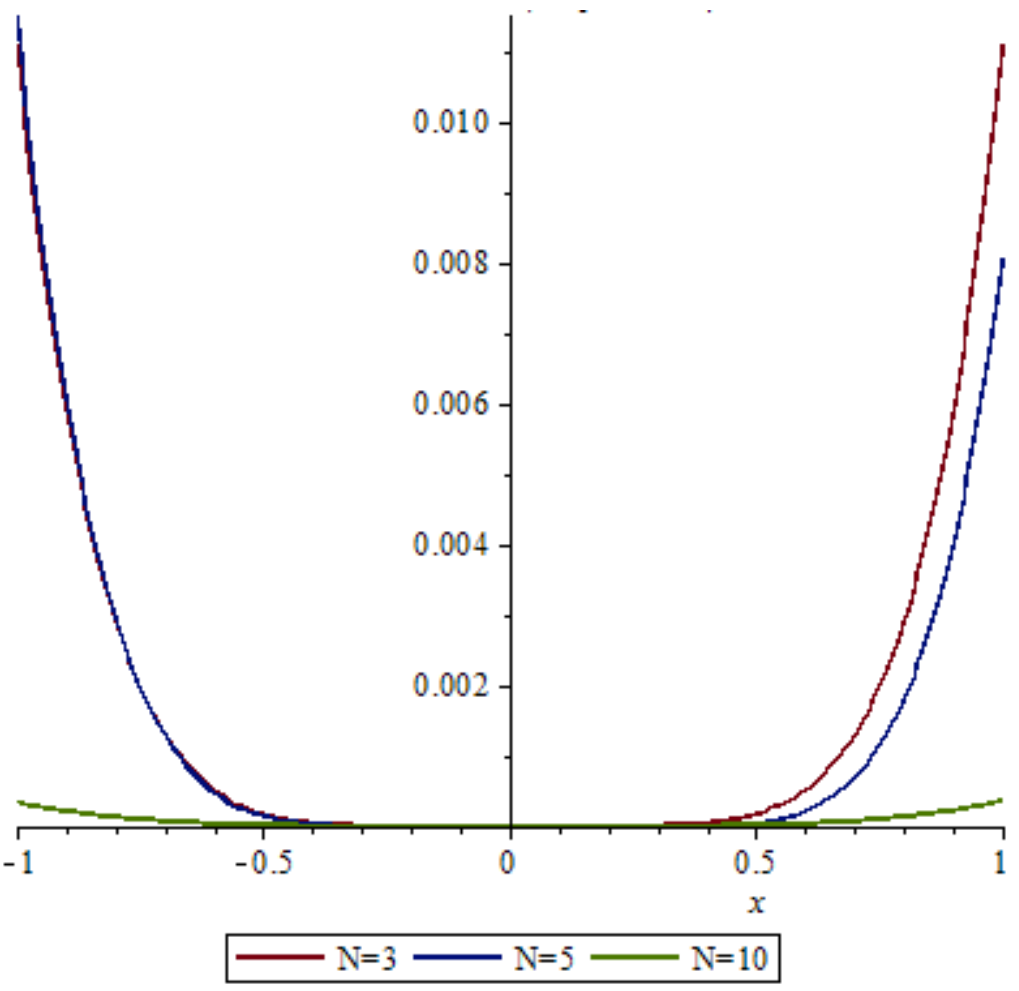

Figure 2. The imaginer parts of the absolute errors functions

Example 2:Finally, consider the linear complex differential equation 


$$
f^{\prime \prime}(z)+2 f^{\prime}(z)+z f(z)=z^{3}+e^{z}(z+3)+6 z+2
$$

with initial conditions $f(0)=3 \quad, f^{\prime}(0)=1$. The exact solution is $f(z)=z^{2}+$ $e^{z}(z+3)+6 z+2$. The next step of our method, we obtain the numerical solution for $\mathrm{N}$ $=3,5,10$. The values of the numerical solution in the issue of $\mathrm{N}=3,5,10$ for both parts of real and imaginary together with the exact solution and absolute errors are supported in figures 3,4,5,6 as follows.

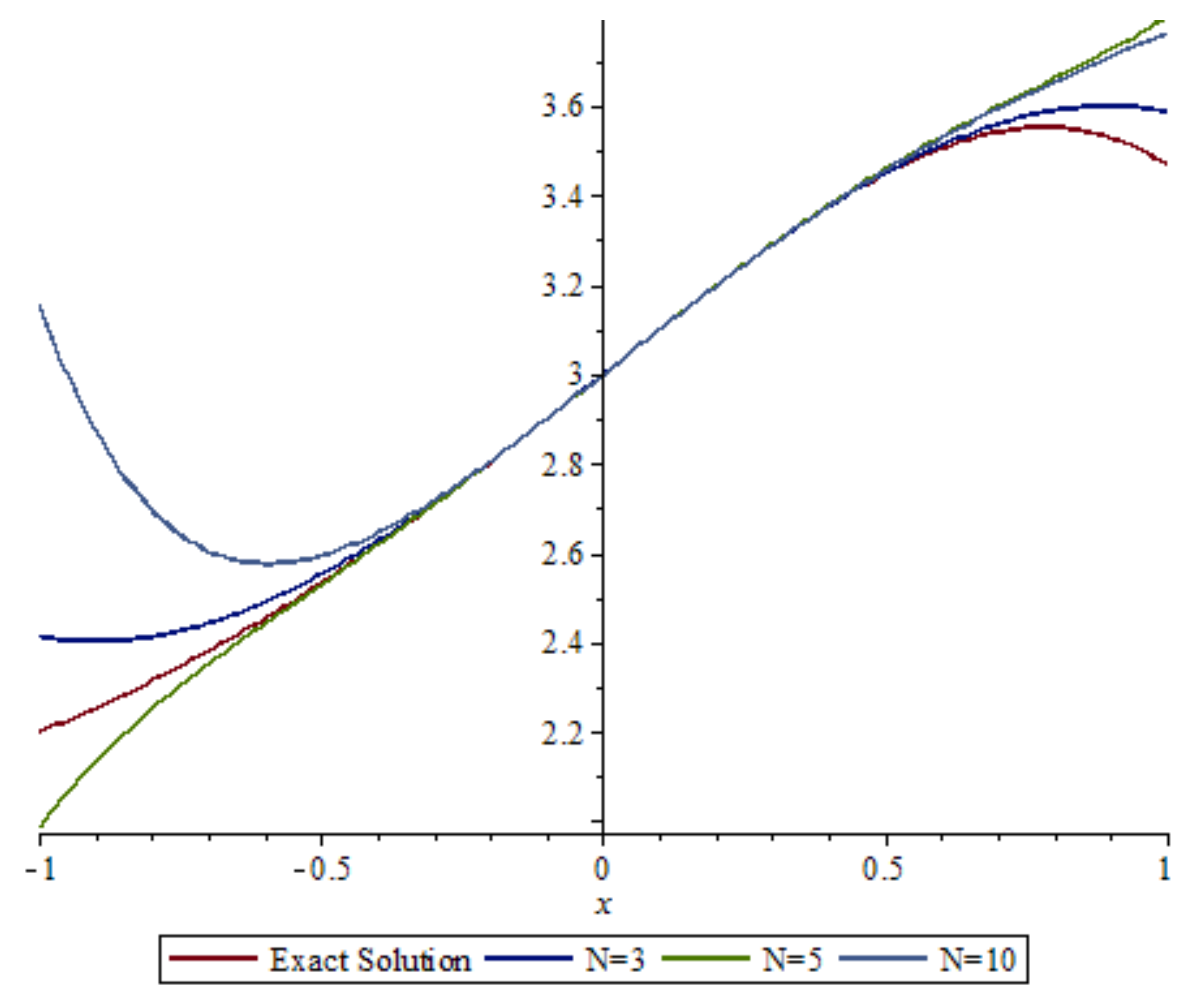

Figure 3. The real parts of the exact solution and numerical one's 


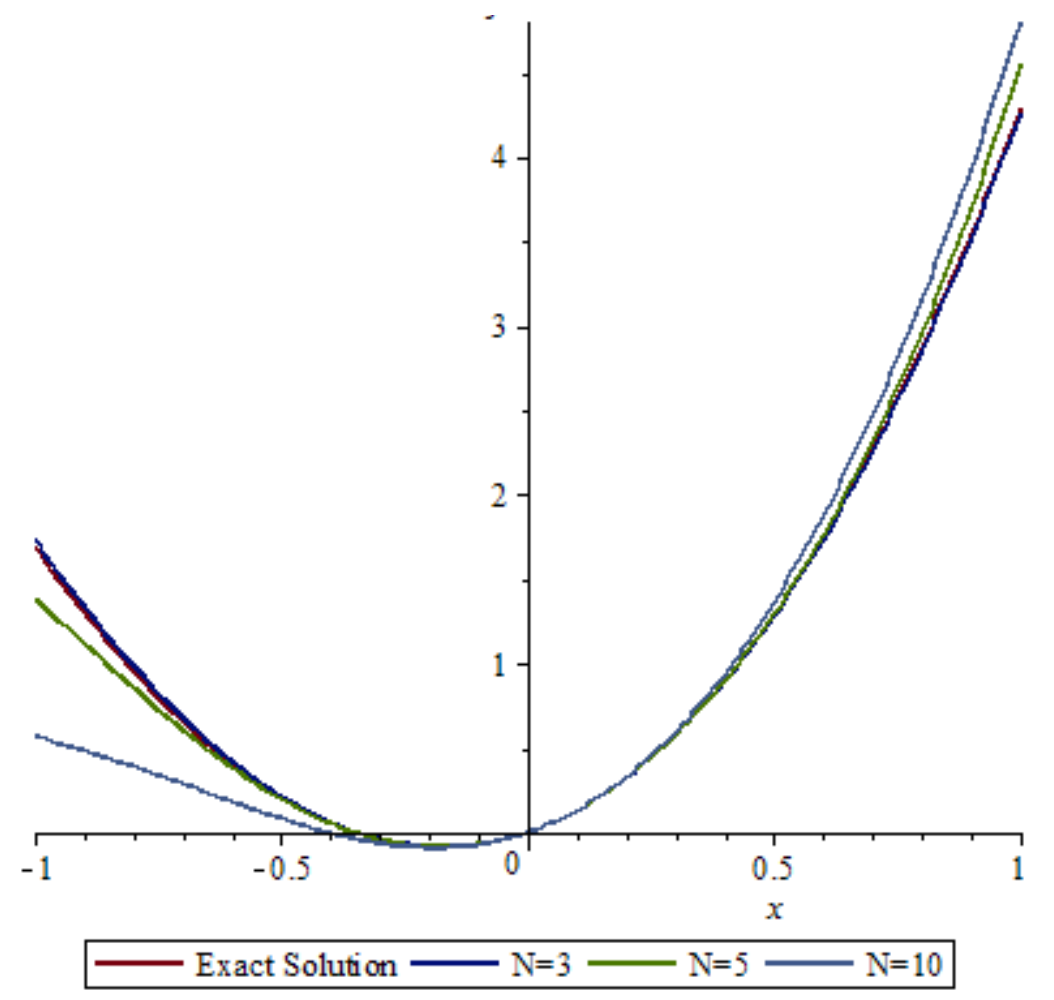

Figure 4. The imaginer parts of the exact solution and numerical one's

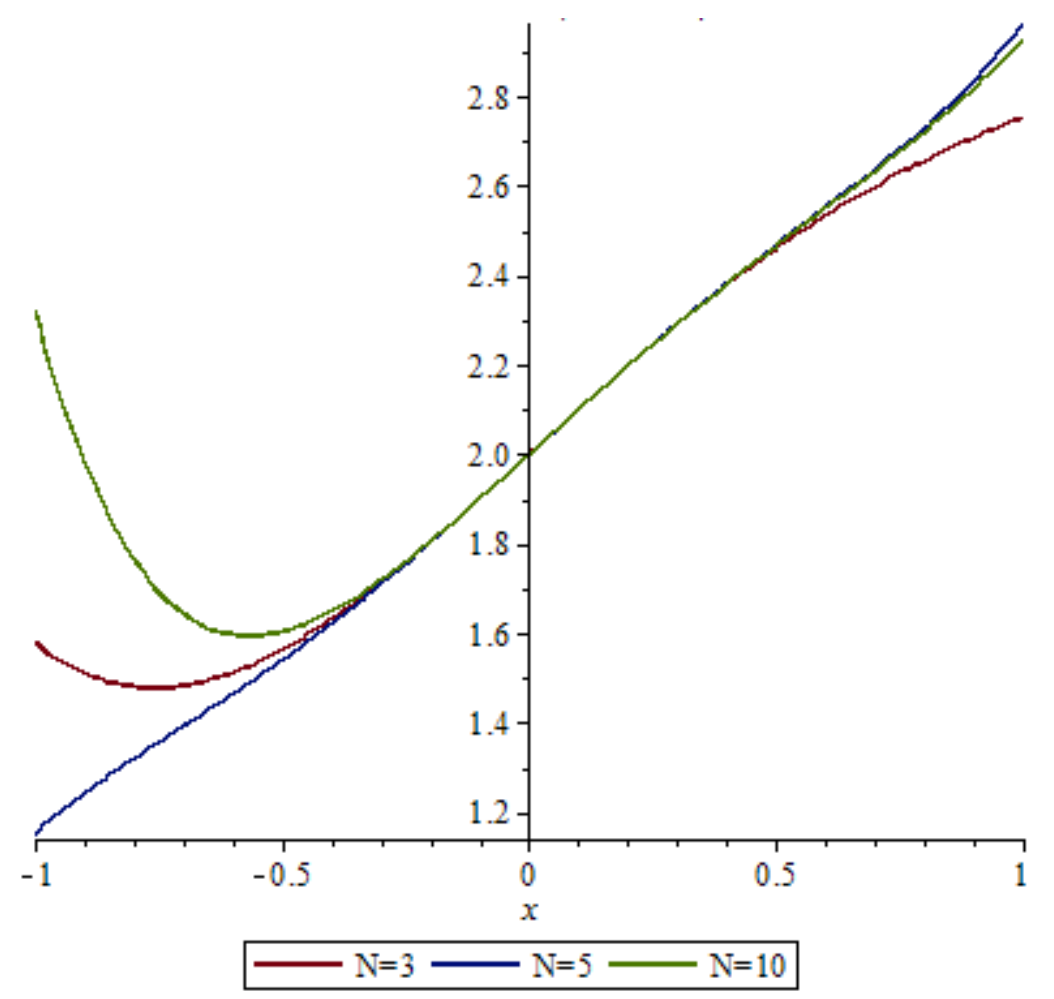

Figure 5. The real parts of the absolute errors functions 


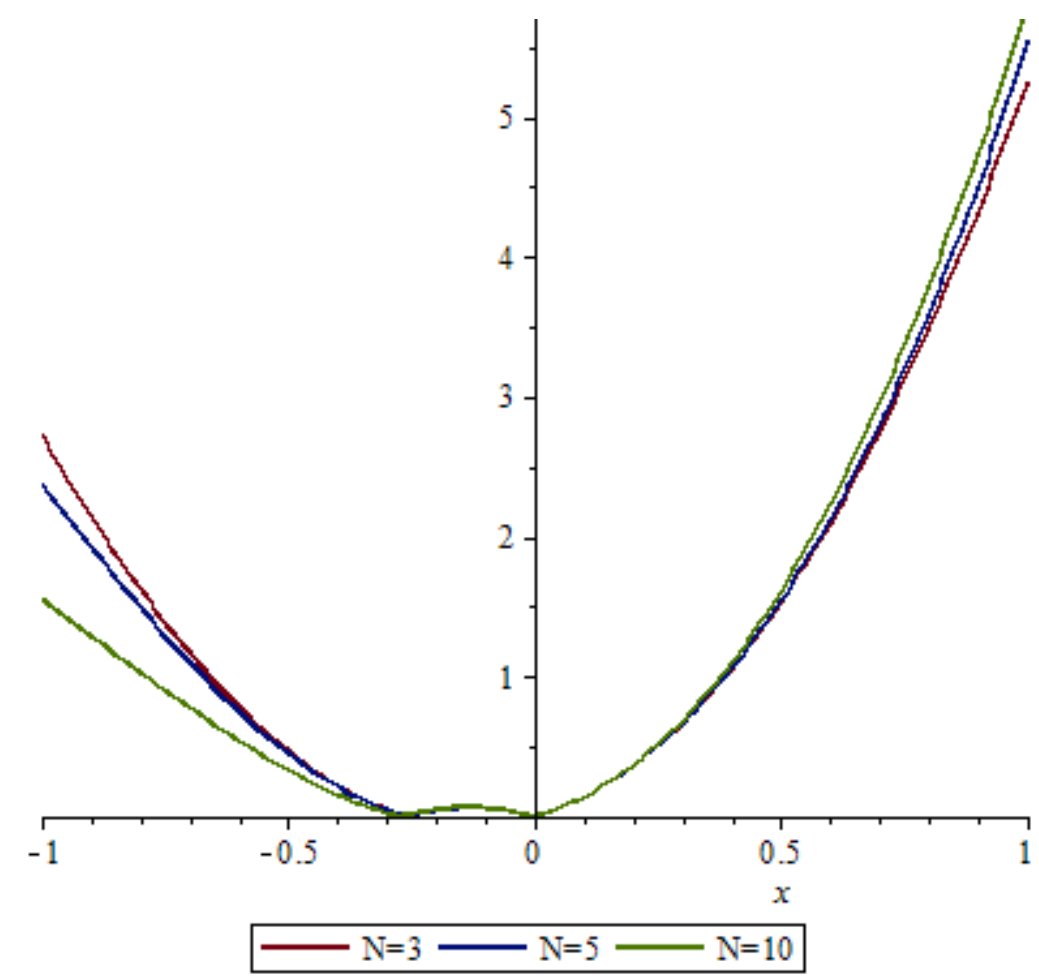

Figure 6. The imaginer parts of the absolute errors functions

\section{CONCLUSIONS}

This way is established on reckoning the coefficients in the Hermite series extension of the solution of a linear complex differential equations providing the circular domain is identified by the functions and. . This way

\section{REFERENCES}

Düşünceli F, Çelik E, 2015. An effective tool: Numerical solutions by Legendre polynomials for high-order linear complex differential equations. British Journal of Applied Science \&Technology, 8(4): 348-355.

Düşünceli F, Çelik E, 2017. Fibonacci matrix polynomial method for linear complex differential equations. Asian Journal of Mathematics and ComputerResearch, 15(3): 229-238.

Gülsu M, Gürbüz B, Öztürk Y, Sezer M, 2011.Laguerre polynomial approach for solving linear delay difference equations.Applied Mathematics and Computation, 217:6765-6776.

Sezer M, Yalçınbaş S, 2009.A collocation method to solve higher order linear complex differential equations in rectangular domains.Numerical Methods for Partial Differential Equations, 26:596-611. is righteous. It may be concluded that the method is an efficient way to discover numerical solutions for linear complex differential equations. On the other hand, the results are quite reliable and good-agreement with the exact solutions. 